\title{
Closing the loop
}

Upcycling plastic waste for carbon capture

\begin{tabular}{|c|c|}
\hline $\begin{array}{l}\text { Two of the most important } \\
\text { environmental concerns of our } \\
\text { times are } \mathrm{CO}_{2} \text { emissions and } \\
\text { plastic pollution. Dr Xiangzhou } \\
\text { Yuan, Research Professor at the } \\
\text { Department of Chemical and } \\
\text { Biological Engineering at Korea } \\
\text { University (Seoul), and Dr Shuai } \\
\text { Deng, Associate. Professor of } \\
\text { Mechanical Engineering at the } \\
\text { School of Tianjin University } \\
\text { (China), propose an approach } \\
\text { that uses one problem to solve } \\
\text { the other. They upcycled waste } \\
\text { plastic bottles to a material } \\
\text { able to attract } \mathrm{CO}_{2} \text { and reduce } \\
\mathrm{CO}_{2} \text { emissions from large point } \\
\text { sources into the atmosphere. } \\
\text { Their approach was shown to } \\
\text { be carbon negative, removing } \\
\text { more } \mathrm{CO}{ }_{2} \text { than required for the } \\
\text { production and operation of the } \\
\text { proposed system. }\end{array}$ & $\begin{array}{l}\text { lastic pollution has become a } \\
\text { housenold term in the past few } \\
\text { years. From the need to recycle } \\
\text { plastic items, to microplastics, to the } \\
\text { islands of plastic waste in the Pacific } \\
\text { Ocean and elsewhere, we have all } \\
\text { become aware of this threatening } \\
\text { environmental concern. Another familiar } \\
\text { concern is the rise of greenhouse gas } \\
\text { emissisions, especially carbon dioxide, } \\
\mathrm{CO}_{2} \text {, which are causing what's known } \\
\text { as 'global warming' or 'climate change'. } \\
\text { These problems have attracted the } \\
\text { attention of the research community, } \\
\text { and the focus on the observation and } \\
\text { solution of issues arising both from } \\
\text { plastic pollution and excessive } \mathrm{CO} \text {, has } \\
\text { resulted in proposals for sustainable } \\
\text { waste management. Despite the overall } \\
\text { progress towards this goal, however, } \\
\text { there have been a few setbacks, with the } \\
\text { most recent one being the COVID-19 } \\
\text { pandemic. Although one could claim that } \\
\text { home working, isolating, and obeying } \\
\text { lockdown rules, might have reduced the } \\
\text { release of } \mathrm{CO} \text { into the atmosphere, this } \\
\text { is not the case with plastic pollution: quite } \\
\text { the opposite. The production of plastic } \\
\text { waste has dramatically increased, with } \\
\text { gloves, masks, facial coverings, single-use }\end{array}$ \\
\hline
\end{tabular}

plastic used to minimise contamination (ang added categories on the long list of Fustic pollution. Furthermore, it is not only production and transportation that contribute to $\mathrm{CO}_{2}$ levels. All activities have a carbon footprint - they release a certain amoun of $\mathrm{CO}_{2}$ at every stage in their cycle. This also applies to the production of plastics, CO, emissions and pollution a'double problem' if you will.

\section{SUSTAINABLE WASTE}

MANAGEMENT

Out of the several categories of plastic responsible for plastic pollution, a dominating one is PET: polyethylene terephthalate. PET is the type of plastic that water bottles, storage jars, and protective packaging materials are made of, and it's creating a global pollution problem. According to metrics for water bottles alone, about $90 \%$ of the water bottles purchased around the world are being discarded to landfill or the and much reve been global efforts the much research devoled to reducing to accelerating PET degradetion (whic, currently takes around 450 years) and into producing types of plastic from more sustainable sources. All these efforts have shown some potential, but unfortunately not enough to give hope for fully sustainable management of plastic
waste. Similarly, there is a great amount of research devoted to $\mathrm{CO}_{2}$ capture and storage, and the reduction of $\mathrm{CO}_{2}$ emissions during the product life cycle. Efforts in this field are also promising, but we are not quite there yet.

Dr Xiangzhou Yuan, Research Professor at the Department of Chemical and Biological Engineering at Korea University (Seoul), and Dr Shuai Den
Associate Professor of Mechanical

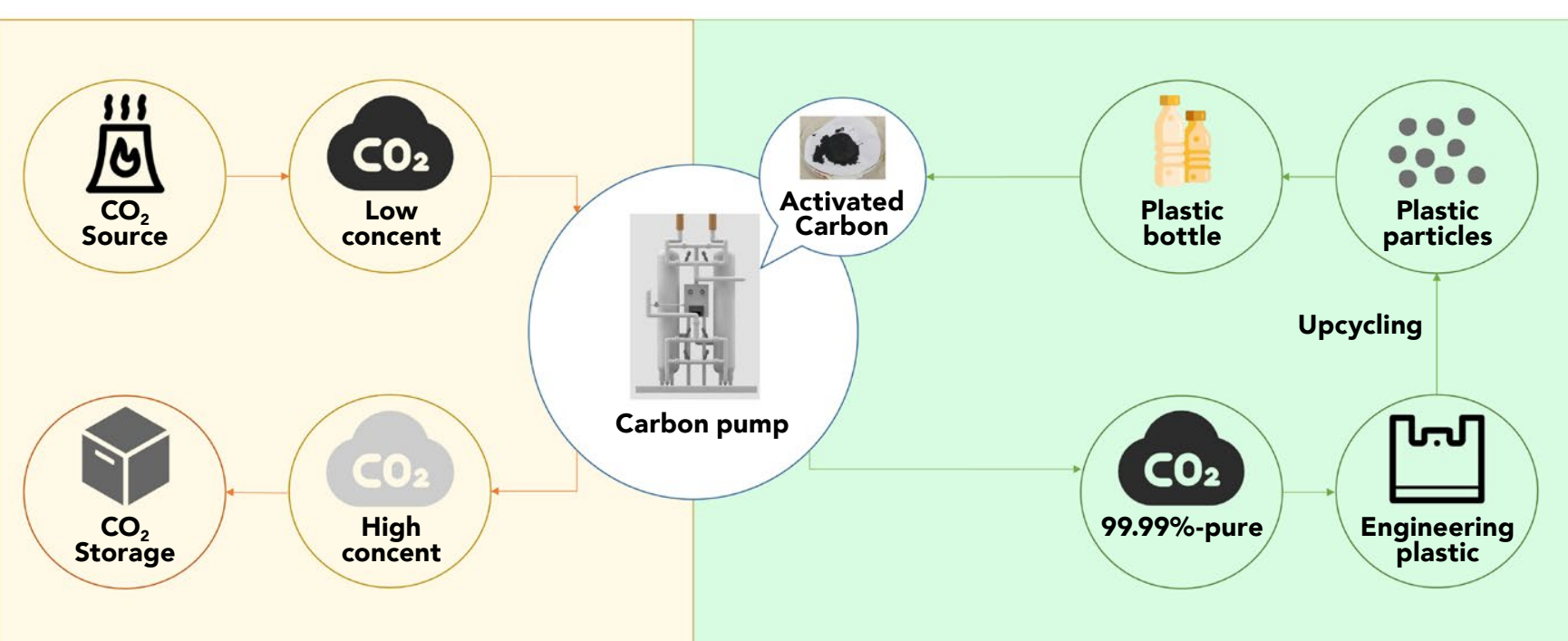

One problem as a solution for another: $\mathrm{PET}$ plastic pollution to enhance $\mathrm{CO}_{2}$ storage by engineering plastic bottles

Engineering at the School of Tianjin better disposal of the plastic bottle University, China, have proposed a afterwards because the activated carbon bottles, starts by subjecting the bottles
new sustainable waste-management approach that shows great potential derived from the plastic botles is in a to to very high temperatures. The resulting for addressing both those problems, it could be further used as a 'sponge' to which means it has adsorbing property by creating a closed carbon and plastic enable cultivation on contaminated soils. whe to the voids that are created on the by creating a closed carbon and plastic enable cultivation on contaminated solis. due to the vocts that are created on the
loop. Whereas research efforts so far have mostly focused on the problems used for soil remediation with or without have burned off. What this means in of pollution and
practice is that this $\begin{array}{ll} & \\ { }^{\mathrm{CO}_{2} \text { emissions }} & \text { The new sustainable waste management } \\ \text { separately, this } & \begin{array}{l}\text { practice is that this } \\ \text { type of material can } \\ \text { suck in gases whose }\end{array}\end{array}$

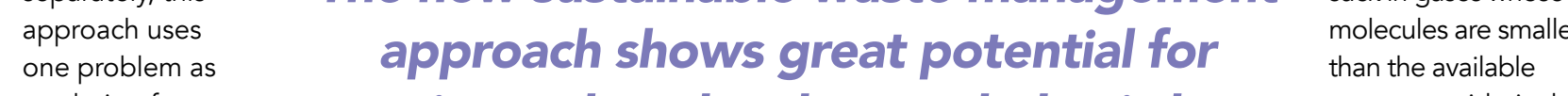
a solution for creating a closed carbon and plastic loop. pores, or voids, in the phe other, using plastic $\mathrm{CO}_{2}$ storage by engineering biochar. This suggests that carbon in and Deng have further enhanced the plastic bottles to capture $\mathrm{CO}_{2}$. activated carbon is finally fixed in the ability of this PET-derived activated carbon

\section{CLOSED CARBON}

Yuan and Deng have explored in detail the use of waste PET for the production of activated carbon that can be used to capture $\mathrm{CO}_{2}$. The min idea behind this innovative approach is to turn plastic waste, specifically water bottles, into a 'sponge' that would adsorb and mitigate $\mathrm{CO}_{2}$ emitted from industries including power plants and cement plants and help transfer it in safe storage. If a bottlesponge could manage to capture an equal or higher amount of $\mathrm{CO}_{2}$ than the amount released during its production, then this would result in a closed carbon and plastic loop.

Creating activated carbon - or a $\mathrm{CO}_{2}-$ adsorbing 'sponge' - out of a PET bottle might sound far-fetched; not only is it
possible, however, but it also enables sequestration and soil health, and there is no solid wastegeneration fron

Yuan and Deng have shown in previous published works that creating this carbonto attract and retain $\mathrm{CO}_{2}$ by introducing met like a and 's 'stick' the this is its adsoring ability To underste adsorbing a little better, imagine a carnivorous plant attracting an insect with its pollen: once the insect is within the

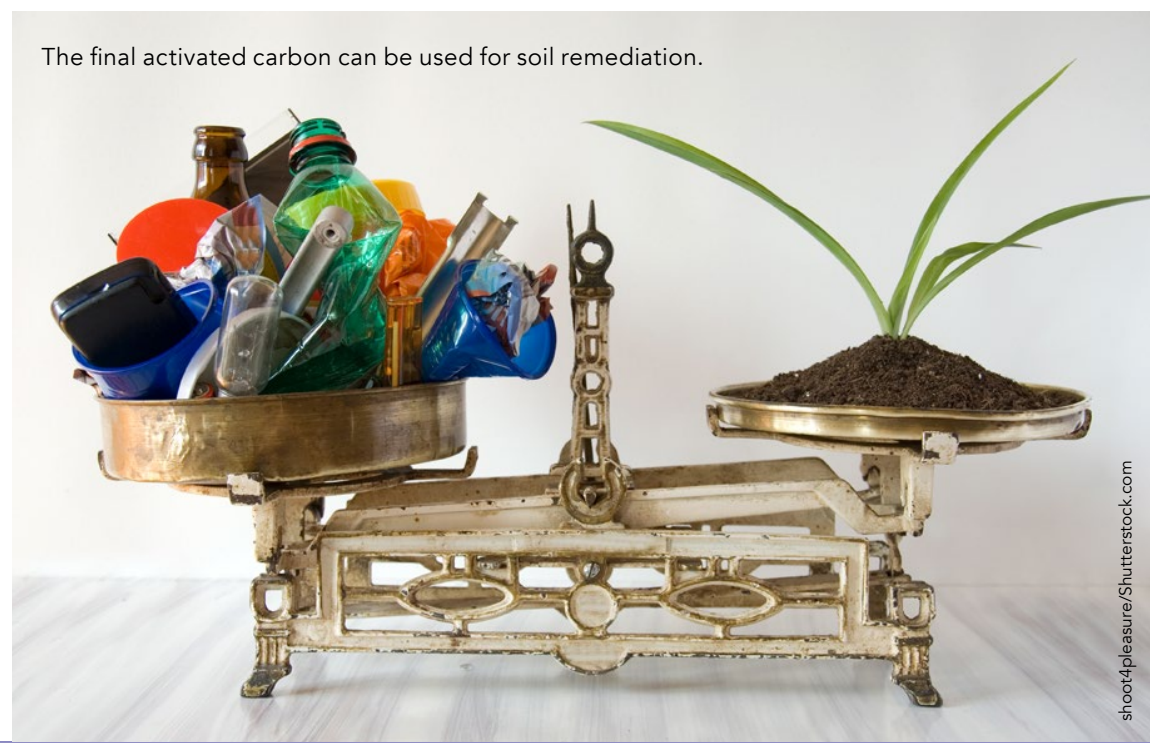




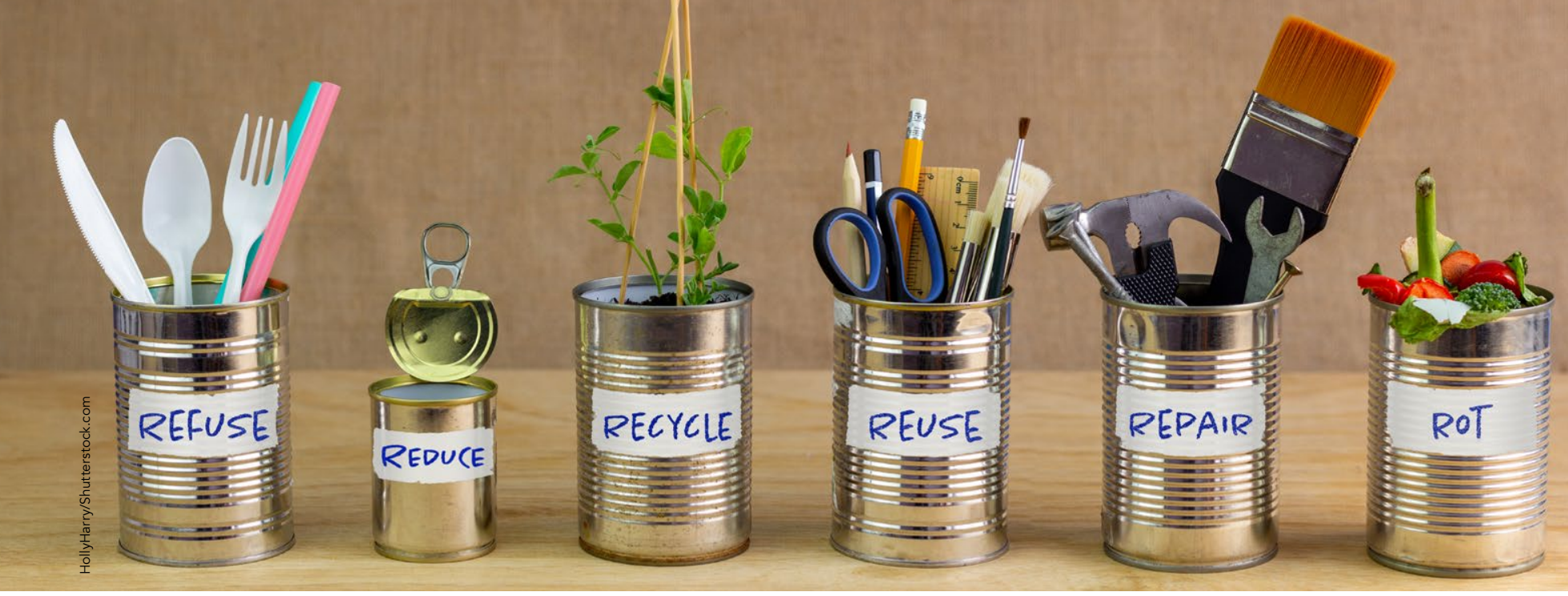
groups are the pollens, and the insect is a $\mathrm{CO}_{2}$ molecule; once the $\mathrm{CO}_{2}$ is close enough to the micropores and function groups (adsorbed whin the pores of the sponge), $\mathrm{t}$ is atracted to it through trapped (adsorbed). The materials used through this process depend on whether these steps would happen one after the other or simultaneously, the introduced properties of the entity chosen to make $\mathrm{CO}_{2}$ stick, and the temperature used to dry off the final product. The researchers tested all these materials to identify the best method for creating the plastic 'sponge'.

\section{MOVING TO LOW-CARBON}

\section{TECHNOLOGY}

As well as working at the experimenta level, Yuan and Deng also did a full

process, asestunent of the proposed step from production to waste: or from production, through checking potential for carbon capture, to waste. The authors compared their findings with information on other similar cycles and procedures. either obtained from their own research could refine their methods for optimal energy and water use, and potential to mitigate global warming. Pivotal to this stage was Dr Deng's previous work on renewable energy resources and how they can be integrated to assist the Using several sensitivity analyses models, the researchers demonstrated that their proposed technique for converting negative. This means that more $\mathrm{CO}_{2}$

was adsorbed by the engineered plastic e of the life cycle of the production, towards a closed carbon and plastic step of the life cycle of the production, loop is far from just an academic
upcycling, and alternative use of the exercise. It supports the achievement

THE FUTURE OF PLASTIC

would be to use the captured $\mathrm{CO}_{2}$ from of UN Sustainable Development Goals such as Goal 11: Sustainable Cities and Communities; Goal 12: Responsible Clucto and Consumption, Goal 13: Water: and Goal 15: Life on Land.

The proposed technique for upcycling plastic waste to $\mathrm{CO}_{2}$-adsorbent was carbon negative.

the upscaled plastic waste. In a recently Developing a sustainable system that published article, Dr Yuan mentioned the synergy between the upcycling of plastic waste and the production of biodegradable plastics, in an effort to support low-carbon technology and mitigates plastic pollution to develop an upscaled vehicle for carbon capture simultaneously relieving two major environmental concerns, is definitely carbon plastic plant, the plant closes around it. In our case, the plastic 'sponge' is the plant, the introduced micropores and functional or from other groups worldwide, so they energy requirements of $\mathrm{CO}_{2}$ capture. - plastic pollution mitigation. Working POLLUTION MANAGEMENT

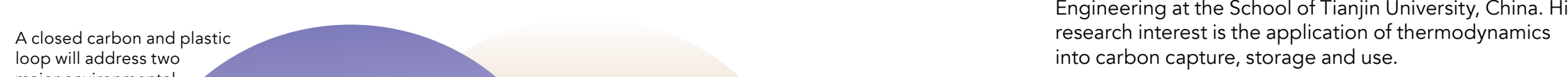
$\begin{array}{ll}\text { major environmentinal } & \text { into carbon } \\ \text { concerns together. } & \text { Funding }\end{array}$

The authors are grateful for the support provided by the China under Grant No 2017YFEO125100, and the of Program of National Natural Science Foundation of China under Grant No. 51876134.

Collaborators

Junyao Wang, Guangdong Research Center for Climate University, China.

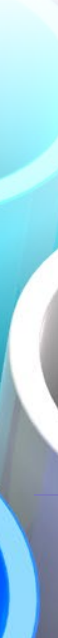

Research Objectives

A new approach to clean energy technology, through
sustainable waste management and carbon capture an storage.

Detail

Xiangzhou Yuan: Department of Chemical \& Biological Engineering, Korea University, 145 Anam-ro, Seongbuk-

Shuai Deng: Key Laboratory of Efficient Utilization of Low and Medium Grade Energy (Tianjin Univers
Education of China, Tianjin 300072, China.

r Xiangzhou Yuan is Research Professor in the Dorea University (Smical and Biological Engineering at Industrial Inc. (South Korea). He mainly specialises in greenhouse gases sorption and separation, sustainable is Associte Professor of Wechagy. Dr Shuai Deng is Associate Professor of Mechanical

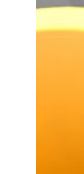
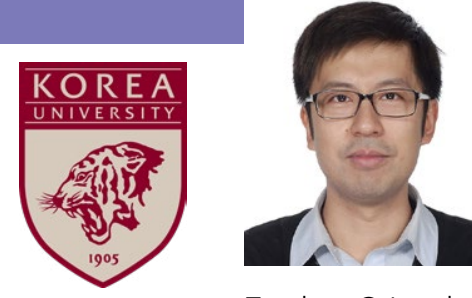

Dr Shuai Deng

Evwniresueducn

W: www.researchgate.net/profile/Shuai-Deng-4

References

Yuan X., et. al. (2021). Dual closed-loop chemical recycling support sustainable mitigation of plastic pollution. Matter, 4,10
matt.2021.03.014

Wang J., et al. (2020). Waste polyethylene terephthalate (PET) plastics-derived activated carbon for $\mathrm{CO}_{2}$ capture: doi.org/10.1039/D0GC01613F

Yuan X., et al. (2020). Valorization of waste polyethylene terephthalate plastic into $\mathrm{N}$-doped microporous carbo for $\mathrm{CO}_{2}$ capture through a one-pot synthesis. J. Hazard. Mater., 399, 123010. doi.org/10.1039/DOGC01613F

Yuan X., et al. (2020). Solving two environmental issues simultaneously: Waste polyethylene terephthalate

plastic bottle-derived microporous carbons for capturing $\mathrm{CO}_{2}$. Chem. Eng. J., 397, 125350. doi.org/10.1016/1: cej.2020.125350

Zhao R., et al. (2017). Carbon pump: Fundamental theory and applications. Energy, 119, 1131. do
org/10.1016/j.energy.2016.11.076

\section{Personal Response}

\section{Could this approach be applied as successfully to plastic} waste other than PET?

III To date, one of the most promising routes to mitigate ubiquitous plastic pollution is to upcycle plastic waste into value-added products including
combustible syngas, liquid fuels, and solid carbons, using thermo-chemical conversions. As it could synergistically and efficiently solve the complicated
challenges from environment protection and challenges from environment protection and sustapose could be applied successfully in a larger range.
propor At the current stage, based on the major research findings, in addition to PET plastic, mixed plastic waste could be considcarthesise activated carbons for capturing $\mathrm{CO}_{2}$. 